\title{
False recognition produced by semantic and phonetic relations under two presentation rates ${ }^{1}$
}

\author{
MOSHE ANISFELD, ${ }^{2}$ Comell University, \\ Ithaca, N.Y. 14850
}

College students listened to a list of 220 words at 2- and 5-sec presentation rates. They had to indicate for each word whether it had appeared before in the list ("yes") or not ("no"). No differences were found between the conditions, becouse, it appears, Ss failed to use in a task-relevant manner the extra time available to them in the longer condition. Words related either semantically or phonetically to previously heard words produced more false-recognition errors/i.e., "yes" responses to new words/ than control words, suggesting that phonetic traces, not only semantic ones, persist for at least $5 \mathrm{~min}$ (this being the maximum separation between a preceding word and a related word).

How are words coded in memory? The successive-presentation technique has recently been applied to answer this question. By this technique, $S$ hears a list of words from a tape recorder and must indicate for each word whether it has appeared before in the list ("old") or not ("new"). The list is so constructed that some of the later new words are related to preceding (P) words, and the analysis consists in comparing the number of "old" responses (false-recognition errors) to the related words with the number of errors to control words. Two studies with college students (Anisfeld \& Knapp, 1968; Underwood, 1965) have shown that semantic relations (e.g., synonymity) are effective in producing false recognition. Can phonetic relations also produce a false-recognition effect? Felzen \& Anisfeld (in press) studied the effects of semantic and rhyming relations on false recognition in third- and sixth-grade children. They found that both factors generally produced false-recognition effects at both age levels, but that the rhyming factor played a relatively stronger role in the younger children and the semantic factor a relatively stronger role in the older children.

The main purpose of the present study was to find out whether a rhyming-relations effect would also be obtained for adults. Wallace (1968) found that for adult Ss, whose sole task was to memorize words in a task similar to that employed by Felzen \& Anisfeld (in press), semantic relations produced a false-recognition effect, but phonetic relations did not. On the other hand, for Ss who had to perform a distracting task along with the memory task, the reverse results were obtained. Similar findings with a different technique were reported by Eagle \& Ortof (1967). An additional exploratory goal of this study was to determine whether rate of presentation influences false recognition. The list of words, including both semantic and rhyming relations, was presented at two rates: in one condition allowing $5 \mathrm{sec}$ between words, and in another condition allowing only 2 sec. Previous experiments with adults (Anisfeld \& Knapp, 1968; Underwood, 1965; Wallace, 1968) used a 10-sec rate, but Ss find this very tedious. Felzen \& Anisfeld (in press) used a 5-sec rate and even the young children found the task comfortable. Their success guided us in the choice of a $5-\sec$ rate for the present study.

$$
\text { METHOD }
$$

The Ss were 48 female students from an introductory psychology course. Twenty-three sets of words were prepared. Each set consisted of five words: a P word, a word semantically related to the $P$ word (S word), a control for the S word (CS), a word which rhymed with the $P$ word $(R)$, and a control for the rhyme word (CR). The $S$ words were mostly antonyms, e.g., sour(P)-sweet(S), and coordinates of the $P$ words, e.g., salt(P)-pepper(S). The range of association between the $P$ and the $S$ words was 213-704 (out of a maximum of 1,000 ) in the Palermo-Jenkins (1964) norms. The control words were chosen to be of the same part of speech, have the same syllabic length, and have roughly the same Thorndike-Lorge (1944) frequency as their respective $S$ and $R$ words. The frequency range of all the words in the sets was 2-AA, with most of the words falling into the $\mathbf{A}$ and $\mathbf{A A}$ categories. An example of a set is: cold(P)-hot(S)brown(CS)-old(R)-glad(CR). The 23 sets were supplemented by 37 filler words, all $A A$, to facilitate list construction in accordance with the description that follows.
Each $\mathbf{P}$ word was repeated once, the second token being 15-29 positions after the first. One experimental word (S or $R$ ) appeared $12-39$ positions after the second $P$ token, and the second experimental word ( $R$ or S) appeared 9.22 positions after the first experimental word. But no experimental word appeared further than 50 positions after the second $P$ token. The control words were within 3 positions either before or after their respective experimental words. Twenty-nine of the filler words appeared twice each, and eight appeared three times each. The total list consisted of 220 words. The first 21 positions in the list were occupied by fillers. From the list designed according to the above description, a second list was constructed by exchanging the positions of the $R$ and $S$ and the $C R$ and $C S$ members within each set. These two lists were recorded under two conditions: at the average rate of a word every $2 \mathrm{sec}$, and at every $5 \mathrm{sec}$.

The Ss were tested individually and instructed to say "yes" for words they had heard before on the list and "no" for new words. Their responses were noted by $E$ and recorded on tape. The Ss were instructed to respond to each word, even if not certain about the response. If they had not responded by the time the next word was heard, they were to ignore the missed word and respond to the word being presented. There were only 11 misses in the experimental and control categories, all in the $2-\mathrm{sec}$ condition. The missed words were prorated in the calculation of false-recognition errors.

Because of the possibility that Ss might misperceive some of the words on the list (see Anisfeld \& Knapp, 1968; Felzen \& Anisfeld, in press), eight new Ss listened to the four recordings (two $S s$ to each recording) and wrote down what they heard. On the basis of these responses, four sets were eliminated from the false-recognition analysis, because the misperceptions involved might have affected differentially the $R$ and the $S$ categories. The 24 words thus eliminated will be treated as fillers in the data analysis.

\section{RESULTS AND DISCUSSION}

Table 1 presents the results of the

Table 1

A Comparison of the False-Recognition Errors to the Experimental and Control Words Under the Two Conditions

\begin{tabular}{|c|c|c|c|c|c|c|}
\hline & $\mathbf{S}$ & & $\mathrm{CS}$ & $\mathbf{R}$ & & CR \\
\hline \multicolumn{7}{|c|}{ 5-Sec Condition } \\
\hline $\bar{x}$ & 1.88 & & 1.38 & 2.50 & & 1.42 \\
\hline$t(47)$ & & $1.96^{*}$ & & & $3.04 * *$ & \\
\hline \multicolumn{7}{|c|}{ 2-Sec Condition } \\
\hline $\bar{x}$ & 1.96 & & .63 & 2.21 & & 1.21 \\
\hline$t(47)$ & & $4.10 * *$ & & & $2.52 * *$ & \\
\hline
\end{tabular}

* 2.02 noeded for significance at the 05 level, two-tailed test $* * 0.02$. 
comparison of the number of false-recognition errors to $R$ words vs $C R$ words and to $S$ words vs $C S$ words under the two timing conditions. It may be seen that all comparisons are significant (one just barely misses the .05 mark). Because of the inordinately low error rate for the CSs in the 2 -sec condition, a direct statistical comparison between the two conditions seems inappropriate. But inspection of Table 1 makes it clear that the two conditions did not differ in the total number of false-recognition errors or in the relative number of $S$ and $R$ errors. In fact, the total percentage of errors for all 220 words, including both false-recognition errors and false-nonrecognition errors (saying "no" to old words) was virtually identical for the two conditions, $2-\sec =7.4 \%, 5-\sec =7.5 \%$. The failure to obtain a difference between the two conditions does not necessarily mean that the time factor plays no role in a recognition task of this sort. As an altemative, it appears quite reasonable to assume that $S s$ in the 5 -sec condition did not use the extra time available to them in a task-relevant manner. Since each word was both a memorization and a test item, it does not seem unlikely that Ss focused attention primarily on the test aspect and, after giving their responses, let the item slip out of their minds in anticipation of the next (test) item. Also, the time interval between presentation of the item and S's re sponse does not appear, from listening to the tapes, to be appreciably longer in the 5 -sec condition than in the $2-\sec$ condition. This interpretation is supported by Ss' comments given in a postexperimental interview. Most of the Ss in both conditions said they did not rehearse or think about a word after giving a response to it.

In both conditions, both semantic and phonetic relations produced false-recognition errors. Why? The phenomenon of false recognition was interpreted earlier (Anisfeld \& Knapp, 1968; see also Anisfeld, 1967) as suggesting that words are not coded wholistically but in terms of the composite of semantic, syntactic, phonetic, and orthographic features characteristic of them. When a word is heard, (some of) these features are activated, and their traces persist in a more or less marked state for some time. False recognition arises when a later word that shares some features with a previous word is presented. The finding that the rhyming relations were as effective in producing false-recognition errors as the semantic relations suggests that the traces of the phonetic features on which rhyming depends retained their marked state as long as the semantic traces did. This finding is in accord with the results of Felzen \& Anisfeld (in press), but at variance with Wallace's
(1968) study, which, it will be recalled, obtained no false-recognition errors for phonetically related words uncer conditions of full attention. The difference in results may be attributable to a difference in the time separation between the $P$ words and the semantically and phonetically related words. The maximum separation in the present experiment was $5 \mathrm{~min}$, and in Wallace's experiment, the minimum separation was $17 \mathrm{~min}$. The longer time may have caused the traces of the phonetic features to fade. This interpretation suggests that phonetic traces fade faster than semantic traces.

\section{REFERENCES}

ANISFELD, M. Review of J. Deese, Associations in language and thonght. American Journal of Psychology, 1967, 80, 646-649.

ANISFELD, M., \& KNAPP, M. E. Association, synonymity, and directionality in false recognition. Journal of Experimental Psychology, 1968, 77, 171-179.

EAGLE, M., \& ORTOF, E. The effect of level of attention upon "phonetic" recognition errors. Journal of Verbal Learning \& Verbal Behavior $1967,6,226-231$.
FELZEN, E., \& ANISFELD, M. Semantic and phonetic relations in the false recognition of words by third- and sixth-grade children. Developmental Psychology, in press.

PALERMO, D. S., \& JENKINS, J. J. Word association norms; grade school through college. Minneapolis: University of Minnesota Press, 1964.

THORNDIKE, E. L., \& LORGE, I. The teacher's word book of 30,000 words. New York: Teachers College, Columbia University, 1944. UNDERWOOD, B. J. False recognition produced by implicit verbal responses. Joumal of Experimental Psychology, 1965, 70, 122-129. WALLACE, W. P. Incidental learning: The influence of associative similarity and formal similarity in producing false recognition. Journal of Verbal Learning \& Verbal Behavior, $1968,7,50-54$.

\section{NOTES}

1. Part of the impetus for this research came from discussions with $U$. Neisser. J. Gall and $K$. Sharon helped in the experiment. This research was supported by Grant GB-13342 from the National Science Foundation.

2. Present address: Department of Psychology, Yeshiva University, New York, N.Y. 10003.

\section{Sex differences in the development of fearfulness:}

\section{A replication}

\section{GORDON W. BRONSON, Mills College, Oakland, Calif. 94613}

Human infants differ in the age at which they first begin to-fear the visually unfamiliar. Among a sample of male infants, a precocious onset of fear was predictive of heightened fearfulness at age 1 year; such developmental continuity was not observed in a comparable female sample. Almost identical patterns were observed in a previous sample; the present replication strengthens the argument for a sex-linked constitutional factor that contributes to the ontogeny of fearfulness.

Although the age of onset will vary somewhat, most human infants begin to be wary of the visually unfamiliar during the middle half of their first year of life. A previous study (Bronson, in press) established that male infants in whom such fear reactions appeared relatively early were significantly more shy of strangers during infancy and into the preschool years; for female infants, however, no such patterns could be established. The present report replicates this finding of a sex difference in developmental continuity in a second sample of human infants.

\section{PROCEDURE}

The data were obtained from Ainsworth's longitudinal study, in which 24 infants were observed in their homes at intervals of 3 weeks throughout the 1st year of life and then tested in an experimentally controlled "strange situation" at age 1 year. 1

The age of onset of fear was inferred from descriptions of the infants' behavior toward the $O$ during the periodic home visits. Original protocols were rated on two scales devised to codify behaviors indicative of fear: Scale $A$ described the infant's smiling behavior toward the $O$, from (1) "Smiled almost immediately" to (5) "Gave no smile to O"; Scale B reflected other indices of fearfulness, from (1) "Showed no evidence of wariness" to (5) "Cried when 0 approached." The distinction between Points 2 and 3 on Scale B deserves special comment. Point 2 was defined as "Looked repeatedly at $O$, but did not seem inhibited by his presence"; Point 3, "Seemed wary of 0 : stared, quieted, for a considerable period." Since infants often show an intense interest in the visually unfamiliar some time before the onset of behavior that can be interpreted as fearful (see Ainsworth, 1967, and Schaffer \& Parry, 1969), only 